\title{
Epidural Cervical Hematoma in a Whiplash Cervical Injury: A Rare Condition
}

\author{
De Matteis A. ${ }^{1}$, Del Fante Z. ${ }^{1}$, Santoro P. ${ }^{1}$, Romano S. ${ }^{1}$, Dell'Aquila M. ${ }^{1}$ \\ ${ }^{I}$ Medical Doctor, Department of Anatomical, Histological, Forensic and Orthopaedic Science, Sapienza University \\ of Rome, Viale Regina Elena 336, 00161 Rome, Italy
}

\begin{abstract}
"Whiplash Injury" describes those injury deriving from the sharp whipping movement of both head and neck, produced at the moment of a traffic accident, particularly following collision from behind, head-on or side collisions. The use of safety belts has led to a reduction in deaths deriving from front-end collisions, but also to an increase in cases of typical whiplash. There are two types of forces that cause whiplash injuries in rear-end car crashes: external forces applied to the body by the seat and head restraint, and internal forces generated by the activation of body's muscles. The combination of these forces causes differential motion of the cervical spine, which results in neck tissues' strain. This event can affect all neck structures: facet joints capsule, muscles, intervertebral disks, nerves and vessels. We report a case of a 68 -year-old woman. The subject, while driving her car, hit head-on a car moving in the opposite direction and died immediately. At autopsy the major findings were limited to multiple rib fractures and fracture of the fifth cervical vertebra with epidural hematoma. This case demonstrates that, even in the absence of direct traumatism, a potentially lethal epidural hematoma may occur as a result of whiplash.
\end{abstract}

Keywords: Whiplash, Epidural Hematoma, Epidural Bleeding, Spinal Cord, Autopsy.

\section{Introduction}

Whiplash is described by Spitzer et $\mathrm{al}^{1}$ as "energy transfer to the cervical spine consequent to an acceleration-deceleration mechanism secondary to car crash or any other collision, which can lead to different tissues' injuries and multiple clinical manifestation, described as whiplash associated disorders". In fact, disorders associated with such indirect traumatic event - whiplash associated disorders (WAD) - could be complex and multifaceted, involving different degrees of both physical and psychological dysfunctions ${ }^{2}$. Its pathophysiology is still unknown and there are no gold standard evaluation procedures. The most frequent symptoms are pain, stiffness and functional

\section{Corresponding Author:}

\section{Paola Santoro}

Department of Anatomical, Histological, Forensic and Orthopaedic Science, SapienzaUniversity of Rome, Viale Regina Elena 336, 00161 Roma

e-mail: paola.santoro@uniroma1.it

Mobile No.: 0649912927 limitation of the cervical spine, headache, and dizziness. These symptoms may associate with pain in other districts ${ }^{3}$ (shoulders, thoracic and lumbar spine), paraesthesia and hypaesthesia, generalized weakness, confusion, and visual and auditory disturbances. Annual incidence of WAD in the general population of North America and Western Europe is circa 300 inhabitants per 100000 and some data suggest a further increase in incidence ${ }^{4-5}$. The use of safety belts has led to a reduction in deaths deriving from front-end collisions, but also to an increase in cases of typical whiplash. We report a case of a 68-year-old woman, who died after a car crush. At autopsy investigation only epidural hematoma emerged as cause of death.

Case Report: A 68-year-old woman, height $158 \mathrm{~cm}$ and weight $72 \mathrm{~kg}$, while driving her car, hit a car headon from the opposite direction. The opposite vehicle was a medium-sized utility car proceeding at an estimated speed of approximately $85-95 \mathrm{~km} / \mathrm{h}$. The vehicle of the deceased woman was also a medium-sized utility car that was traveling at a speed of approximately 70-90 $\mathrm{km} / \mathrm{h}$. The woman was wearing seat belt and her car had 
no headrest in the front seats.Investigations of the event showedregular airbags functioning during the accident. After the accident the woman died immediately. Based on the information provided by some family members, the driver had no notable pathologies. All toxicological investigations were negative.During autopsy, there wasnot external signs consistent with fatal injuries. Small bruising in various body districts were the only external findings. They were located to both face and neck, presumably being related to the impact with airbag.Internal examination revealed no lesionsof the cranium. The brain showed no gross alterations, except for rare petechial hemorrhages throughout the cerebral peduncles. No otherlesion affected the abdominal viscera. At the thoracic level, even though the sternum was found intact, four ribson the left side of the thoracic cage were found to be fractured. Soft tissues and neck'sstructures had no detectable lesions but,after removal of superficial structures, a considerable blood infiltration of the perivertebral muscles was evident(Figure 1A). There was a full thickness fracture of the fifth cervical vertebra body (compression fracture) with concomitant blood infiltration of cancellous tissue.An anterior approach to the spinal cord was performed at that level: both leptomeninges and dura mater were undamaged, while opening of the vertebral canal confirmed the presence of epidural hemorrhagewith spinal cord compression (Figure 1B-2C). At the level of the spinal cord, the execution of parallel transverse cuts at a distance of 1 $\mathrm{cm}$, allowed to detect small spinal hemorrhages. The examination of the remaining organs appeared devoid of elements worthy of note (no a cardiac contusion). Histological investigation confirmed both epidural and intra-parenchymal hemorrhages (Figure 2). Results of toxicological analysis were negative.Subject'sdeath was caused by irreversible spinal cord injury resulting in cardiorespiratory arrest. Damage of the spinal column and spinal cord was caused by the kinetic energy developed due to acceleration-deceleration mechanism. This dynamic caused vertebral fracture, epidural and spinal cord hemorrhages, leading to a spinal cord injury.
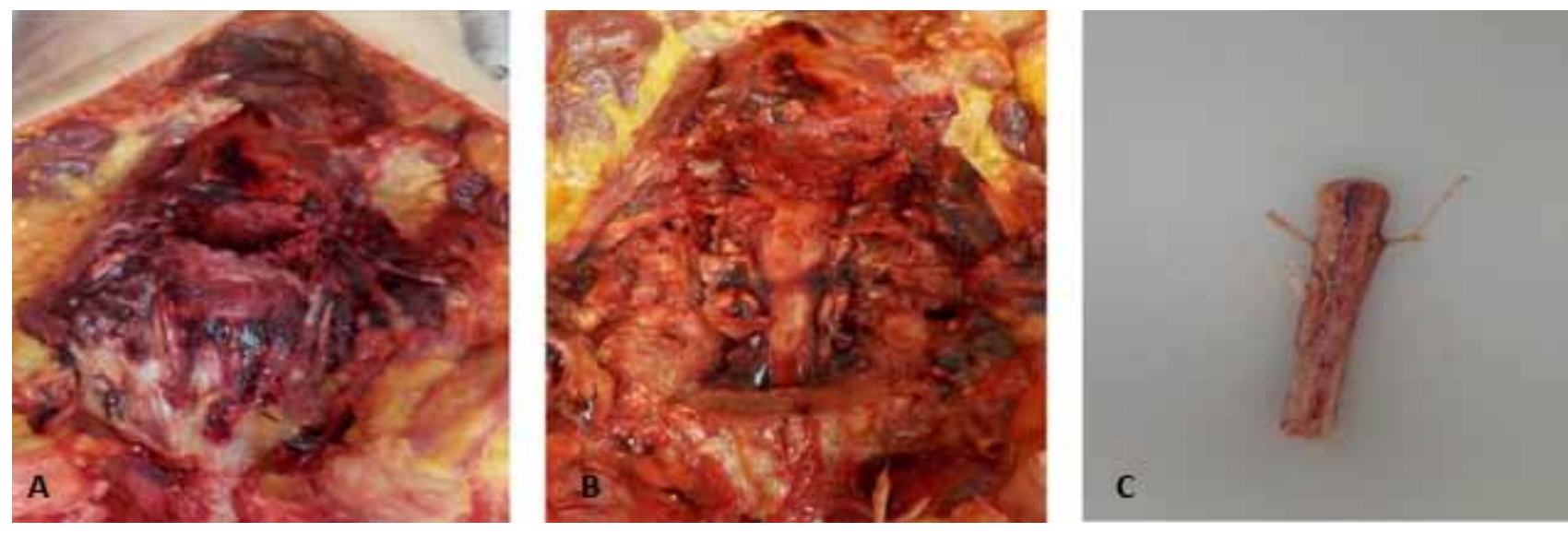

Figure 1: (A) Blood infiltration of peri-vertebral soft tissues and muscles; (B,C)Epidural hemorrhage with spinal cord compression after the opening of the vertebral canal.
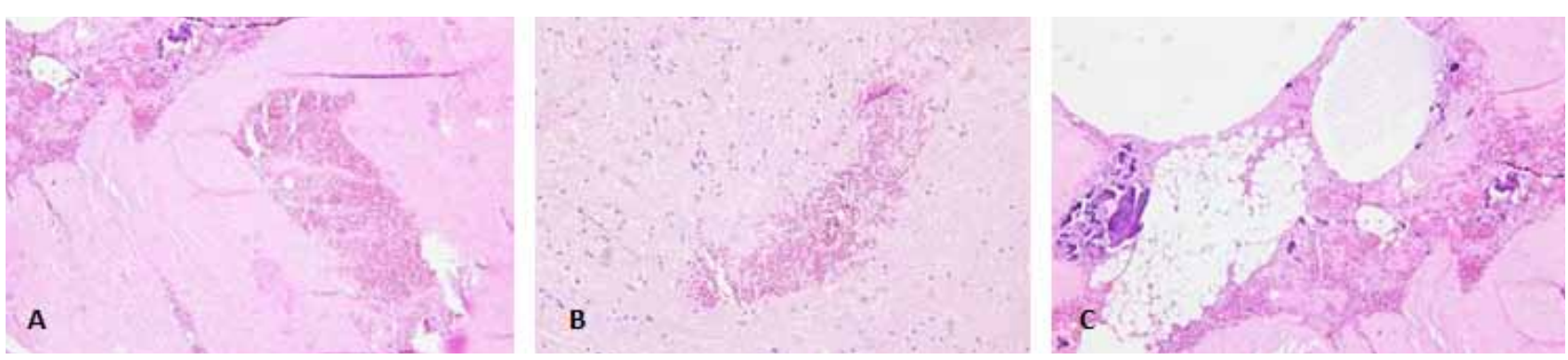

Figure 2: Epidural (A) and intra-parenchymal (B) hemorrhages viewable by optical microscopy with hematoxylin-eosin staining. (C) Multiple red cell collections with consensual interruption of the bone structure. 

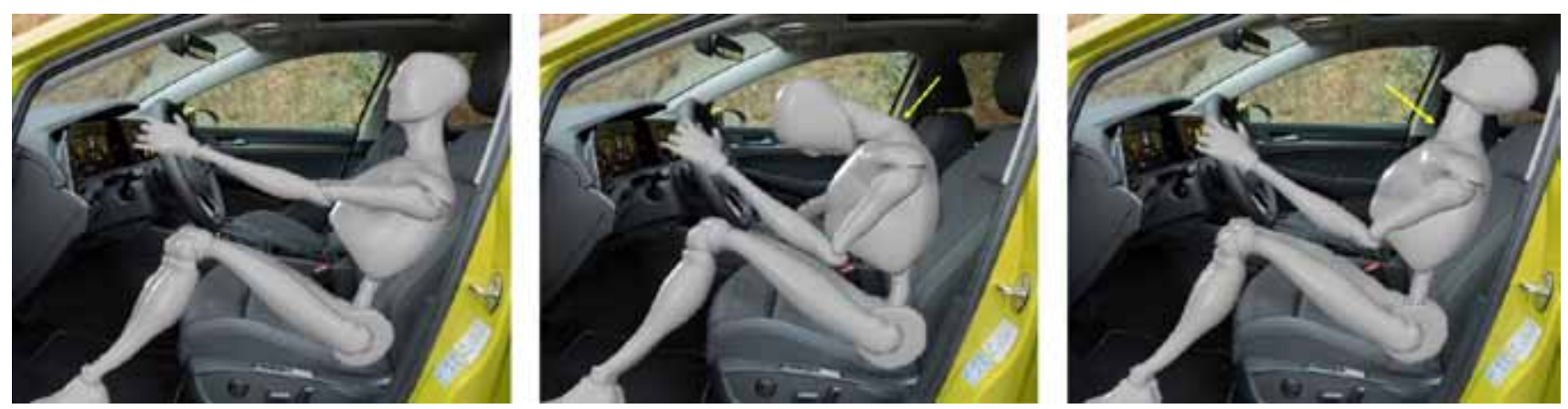

Figure 3: Pathological mechanism of whiplash injury. Poser ${ }^{\circledR}$ software on a MacOSX ${ }^{\circledR}$ device was used for $3 D$ reconstruction of the event.

\section{Discussion}

Whiplash Injury is characterized by different symptoms occurring following damage to the neck, usually as a result of sudden strain affecting discs, muscles, nerves or tendons. It is caused by a sudden acceleration or deceleration of both head and neck. The head is violently thrown back, forwards, or sideways followed, usually, by reflex contraction of the muscles in the opposite direction. Sometimes instead, the projection is one-directional ${ }^{6}$ (Figure 3).

In the reported case, it could be argued that damage from hyperextension was prevalent, given the absence of headrest, correct functioning of airbags and rupture of the anterior longitudinal ligament associated to compression fracture of the vertebral body, found during autopsy.

The pathophysiological mechanisms, clinical and symptomatologic characteristics of whiplash are widely described in literature ${ }^{7-11}$. Therapeutic approach to whiplash has also been analyzed by studies evaluating the benefits of physiotherapy ${ }^{12,13}$. After a brief review of the literature, we found that there are no studies describing possible lethal acute mechanisms of whiplash, except for a study describing an unusual case of post-whiplash pseudoaneurysm of the right common carotid artery, which led to acute massive hemorrhage and death, days after initial trauma ${ }^{14}$.

We describe a very rare condition: formation of epidural hematoma following whiplash injury. Spinal epidural hematomasare a rare occurrence, accounting for less than $1 \%$ of all spinal canal space-occupying lesions ${ }^{15}$. There are two main types of spinal epidural hematomas: spontaneous and traumatic. The first, most frequent, is often associated with vascular malformations, coagulopathies, anticoagulation, neoplasms, or thrombocytopenia ${ }^{16-18}$. The latter, rarer, occurs frequently in patientsaffected by rheumatologic diseases, such as ankylosing spondylitis and rheumatoid arthritis ${ }^{19}$. Although, it is not clear what caused the epidural hemorrhage following fracture of a cervical vertebra, one of the hypotheses is that a bone fragment damaged epidural vessels, resulting in bleeding within epidural space ${ }^{20}$. Furthermore, the spinal bleeding can also be linked to the tearing of the microvasculature that supplies brainstem and spinal cord.

\section{Conclusion}

The current case is somewhat different from any previously described one. In fact, diffuse epidural hemorrhage, with development of small hemorrhages in the spinal cord, secondary to fifth cervical vertebra fracture due to whiplash, occurred in a patient without comorbidity. This particular succession of pathological events, moreover, was the cause of death of the patient.

Conflict of Interest: The authors declare that they have no conflicts of interest.

Ethical Approval: This paper was approved by all authors.

Informed Consent: Informed consent was obtained from the Judicial Authority for whom identifying information is included in this article.

\section{References}

1. Spitzer WO, Skovron ML, Salmi LR, et al. Scientific monograph of the Quebec Task Force on Whiplash-Associated Disorders: redefining "whiplash" and its management.Spine. 1995; 20: $1 \mathrm{~S}-73 \mathrm{~S}$. 
2. Craig A, Tran Y, Guest R, et al. Psychological impact of injuries sustained in motor vehicle crashes: systematic review and meta-analysis. BMJ Open. 2016; 6: e011993.

3. Chauhan SK, Peckham $\mathrm{T}$ and Turner R. Impingement syndrome associated with whiplash injury. J Bone JointSurg. 2003; 85: 408-410.

4. Holm LW, Carroll LJ, Cassidy JD et al. The burden and determinants of neck pain in whiplashassociated disorders after traffic collisions; Bone and Joint Decade 2000-2010 Task Force on Neck Pain and Its Associated Disorders. Spine. 2008; 33(4 Suppl): S52-9.

5. Kamper SJ, Rebbeck TJ, Maher CG, Mcauley $\mathrm{JH}$, Sterling M. Course and prognostic factors of whiplash: a systematic review and meta-analysis. Pain. 2008; 138(3): 617-29.

6. Adams Vernard I. Neck Injuries: I, II and III Journal of Forensic Sciences, JFSCA. 1992; 37(2) and 38(5).

7. Stemper B, Yoganandan N, Pintar F, Rao R. Reflex muscle contraction in the unaware occupant in whiplash injury. Spine. 2005; 30:2794-2798.

8. Panjabi MM, Cholewicki J, Nibu K, Grauer JN, Babat LB, Dvorak J. Mechanism of whiplash injury. Clin Biomech. 1998; 13(4-5):239-249.

9. Gitto L, Serinelli S, Busardò FP, et al. Can postmortem computer tomography be considered an alternative for autopsy in death due to hemopericardium? Journal of Geriatric Cardiology. 2015; 11(4): 363-67.

10. Arunkumar P, Maiese A, Bolino G, Gitto L. Determined to die! Ability to act following multiple self-inflicted gunshot wounds to the head. The Cook County Office of Medical Examiner experience (2005-2012) and review of the literature. J Forensic Sci.2015; 60(5): 1373-79.

11. John JD, Saravana Kumar G, Yoganandan N. Rear-impact neck whiplash: Role of head inertial
Medico-legal Update, April-June 2021, Vol. 21, No. 2

properties and spine morphological variations on segmental rotations. J Biomech Eng. 2019; Epub ahead of print.

12. Sterling M. Physiotherapy management of whiplash-associated disorders (WAD). J Physiother. 2014;60(1):5-12.

13. Rebbeck T. The Role of Exercise and Patient Education in the Noninvasive Management of Whiplash. J Orthop Sports Phys Ther. 2017; 47(7):481-491.

14. Pomara C, Bello S, Serinelli S, Fineschi V. A rare and lethal case of right common carotid pseudoaneurysm following whiplash trauma. Forensic Sci Med Pathol. 2015;11(1):69-73.

15. Al-Mutair A, Bednar DA. Spinal epidural hematoma. J Am Acad Orthop Surg. 2010;18:494502.

16. Figueroa J, DeVine JG. Spontaneous spinal epidural hematoma: literature review. J Spine Surg. 2017; 3(1): 58-63.

17. Maiese A, Gitto L, Dell'Aquila M, Bolino G. Apeculiar case of suicide enacted through the ancient Japanese ritual of Jigai. Am J Forensic Med and Path.2014;35(1): 8-10.

18. Gitto L, Bonaccorso L, Maiese A, et al. A scream from the past: a multidisciplinary approach in a concealment of a corpse found mummified. $\mathrm{J}$ Forensic Legal Med.2015;32: 53-8.

19. Elgafy H, Bransford RJ, Chapman JR. Epidural hematoma associated with occult fracture in ankylosing spondylitis patient: a case report and review of the literature. J Spinal Disord Tech.2011; 24:469-73.

20. Thumbikat P, Hariharan RP, Ravichandran G, et al. Spinal cord injury in patients with ankylosing spondylitis: a 10-year review. Spine. 2007; 32:2989-95. 